\title{
Efeito da vacinação contra a Mastite Estafilocócica sobre a associação de Staphylococcus sp. a células do leite*
}

\author{
Effect of the vaccination against Staphylococcal Mastitis \\ on the association of Staphylococcus sp. to milk cells
}

\author{
Vagner Miranda Portes, Camila Wolff, Adil Knackfuss Vaz \& William Dick
}

\begin{abstract}
RESUMO
A mastite estafilocócica ocasiona prejuízos consideráveis aos produtores, à industria leiteira e aos consumidores. O controle desta doença através de vacinação resulta numa proteção modesta, o que tem inibido a utilização de vacinas pelos criadores. Para avaliar o efeito da vacinação sobre um dos principais mecanismos imunológicos de defesa, foram utilizados dois grupos de cinco animais, sendo um vacinado com vacina comercial $\left(\right.$ MASTAPH $\left.^{\circledR}\right)$ e o outro não vacinado. Foi provocada uma mastite transitória e estéril nestes animais, através da aplicação de endotoxina de Escherichia coli em um quarto mamário, para a obtenção de células inflamatórias. As amostras foram dividas em: animais vacinados e não vacinados; com ou sem opsonização prévia das amostras bacterianas; e utilização de cepas de Staphylococcus aureus e de Staphylococcus sp. para a observação de fagocitose. As células foram colocadas em contato com as cepas de estafilococos por meia hora, para desencadear o processo de fagocitose e adesão celular. Posteriormente, foram feitos esfregaços em lâminas, utilizando-se a coloração de Wright, e contadas as células bacterianas aderidas às células. A contagem foi feita em duplicata, por dois operadores diferentes. Os resultados obtidos foram submetidos à análise estatística (Teste de $t$ não pareado), onde se verificou um aumento significativo na associação de bactérias às células inflamatórias nos animais vacinados, tanto quando a amostra bacteriana utilizada era Staphylococcus sp. ou S. aureus $(\mathrm{p}<0.01)$. O prévio tratamento das bactérias com soro imune aumenta significativamente o número de bactérias associadas a células $(\mathrm{p}<0.01)$. Concluiu-se que a utilização desta vacina comercial para mastite estafilocócica mostrou-se eficaz, aumentado a associação de Staphylococcus sp. a células inflamatórias do leite.
\end{abstract}

Descritores: mastite, Staphylococcus sp., imunoglobulinas, fagocitose.

\section{ABSTRACT}

Staphylococcal mastitis causes considerable economic losses to the producer, the milk industry and to the consumers. The control of this disease through vaccination results in a modest protection, and this has inhibited its use. This experiment was designed to evaluate the effect of a commercial vaccine against staphylococcal mastitis on the association of this bacterium to milk cells. Two groups of five animals each were utilized. One was vaccinated with a a commercial vaccine (MASTAPH ${ }^{\circledR}$ ), as per the manufacturer's recommendation and the other was left unvaccinated. Inflammation was induced in one quarter of the mammary gland of all animals, by the infusion of Escherichia coli endotoxin, to obtain inflammatory cells. The samples were further divided as follows: vaccinated and unvaccinated animals; previous opsonization of the bacterial strains and no opsonization; phagocytosis and adhesion of a Staphylococcus aureus strain of Staphylococcus sp. Cells were co-incubated with the bacteria for $1 / 2$ hour, to trigger the adhesion and phagocytosis process. After that, slides were prepared, and the number of bacteria associated to cells was counted. The counts were made in duplicate, and by two different operators. The results obtained were statistically analyzed using the unpaired $t$ test. It was found a significant increase in the number of bacteria associated to inflammatory cells in vaccinated animals, irrespective to when the bacterial sample used was Staphylococcus sp. or S. aureus ( $<0,01)$. The previous treatment of the bacteria with immune serum significantly increased the number of bacteria associated to cells $(\mathrm{p}<0,01)$. It was concluded that the vaccine used in this experiment was able to increase Staphylococcus sp. association to milk cells.

Key words: Mastitis, Staphylococcus sp., Immunoglobulins, Phagocytosis. 


\section{INTRODUÇÃO}

Dentre as doenças que atingem a pecuária leiteira, a de maior importância em termos econômicos é a mastite estafilocócica [2]. O Sthaphylococcus sp. é o agente mais frequientemente isolado de amostras de leite proveniente de vacas com mastite $[6,16,20]$. $\mathrm{O}$ controle da mastite depende mais da prevenção que de tratamentos [4], sendo o aumento da capacidade de resposta imune do animal, através de vacinação contra agente especifico, uma importante estratégia de controle [18]. Vacinas contra esta doença têm efeito limitado, atuando como um paliativo para a redução das perdas $[3,24]$. O uso destas vacinas torna-se uma decisão econômica para veterinários e criadores, pois reduz custos e tem reflexos positivos sobre a qualidade do leite e a saúde pública, ao reduzir a necessidade do uso de antibióticos. Estudos mostram uma potencialização da antibioticoterapia associada a vacinação, elevando os índices de cura de 20 a 30\% para 70 a $80 \%$ [19,23]. O mecanismo de ação desta vacina foi apenas parcialmente elucidado, mas acredita-se que a presença de opsoninas do tipo IgG2 facilita a opsonização das bactérias e a sua fagocitose, pois neutrófilos de ruminantes têm receptores de membrana para o fragmento $\mathrm{Fc}$ deste isotipo de imunoglobulina [5,8,13-15,17]. Além disso, a IgA atuaria, como em outros epitélios, dificultando a adesão das bactérias [12]. Este isotipo também é o primeiro a interagir com as proteínas dependentes de ferro expressas in vivo por diversas espécies bacterianas [10]. Avaliou-se a eficácia do uso de vacina através do estimulo à fagocitose e adesão bacteriana por células do leite, pois este é um dos mecanismos aceitos para proteção da glândula mamária.

\section{MATERIAIS E MÉTODOS}

Os índices de fagocitose e adesão bacteriana foram medidos in vitro, associando células inflamatórias do leite a Staphylococcus sp. Foram utilizadas células oriundas de secreção mamária de dois grupos de vacas, um não vacinado e outro vacinado com uma vacina comercial contra a mastite estafilocócica (MAS$\mathrm{TAPH}^{\circledR 1}$ ). As células foram obtidas através da inoculação intramamária de endotoxina, produzindo uma mastite estéril e transitória. Quanto às amostras bacterianas, foram utilizadas cepas de Staphylococcus aureus e de Staphylococcus sp. Cada amostra bacteriana foi subdividida em dois grupos: com e sem opsonização prévia por soro imune. Os neutrófilos foram colocados em contato com as cepas de estafilococos por meia hora a $37^{\circ} \mathrm{C}$, para desencadear o processo de fagocitose e adesão celular. Posteriormente, foram feitos esfregaços em lâminas, utilizando-se a coloração de Wright e contadas as células bacterianas aderidas às células inflamatórias.

\section{Animais}

Foram utilizados dois grupos de cinco vacas, livres de mastite, monitoradas através de CMT (California Mastitis Test) e exames microbiológicos semanais. $\mathrm{O}$ grupo $\mathrm{A}$ foi vacinado conforme recomendação de bula da vacina comercial utilizada (MASTAPH ${ }^{\circledR 1}$ ), ou seja, duas doses com intervalo de três a quatro semanas. A vacina contém Staphylococcus aureus capsulado e capaz de resistir à deficiência de ferro, alem de apresentar um adjuvante que estimula a produção de IgG2. O grupo B foi constituído de animais não vacinados, isto é, o grupo controle.

\section{Amostras bacterianas}

Foram utilizadas para a observação de fagocitose duas amostras de Staphylococcus sp.: uma amostra coagulase positiva, manitol positiva e produtora de pseudocápsulas de acordo com a técnica do "Serum Soft Agar" [22], e outra de um estafilococo coagulase negativo e não produtor de pseudocápsula.

\section{Obtenção de neutrófilos}

Duas semanas após a segunda dose da vacina, os animais foram inoculados via intramamária em um quarto mamário com endotoxina de Escherichia coli, para induzir uma mastite estéril e transitória. A secreção mamária destes animais foi assepticamente coletada cerca de 12 horas após a inoculação e mantida refrigerada a temperatura de $5^{\circ} \mathrm{C}$ durante toda a execução do experimento. A dose de endotoxina utilizada foi de $3 \mathrm{ml}$, constituído pelo sobrenadante de um cultivo de 24 horas de uma amostra sabidamente toxigênica de Escherichia coli (E. coli 68). Em laboratório, a secreção mamária foi centrifugada por $30 \mathrm{~min}$, a $300 \mathrm{~g}$ para a retirada da gordura. Após a retirada da camada de gordura, o "pellet" foi ressuspendido em PBS estéril tamponado, na temperatura de $5^{\circ} \mathrm{C}$ e centrifugadas por $15 \mathrm{~min}$, a $350 \mathrm{~g}$. As células foram submetidas a uma terceira centrifugação para a retirada dos resquícios de fibrina.

\section{Avaliação da fagocitose}

As amostras foram divididas em: 1 - animais vacinados e animais não vacinados; 2 - utilização de 
soro imune (soro de vacas vacinadas) para opsonização prévia das amostras bacterianas, e não utilização de soro para opsonização; 3 - utilização de cepas de Staphylococcus sp., sendo uma amostra coagulase positiva e produtora de pseudocápsulas, e outra coagulase negativa e não produtora de pseudocápsula. Cerca de 4 horas antes de serem colocadas em contato com o soro imune, as amostras bacterianas foram cultivadas em TSB (Trypitic Soy Broth) a $37^{\circ} \mathrm{C}$, e depois centrifugadas a $300 \mathrm{~g}$ por $15 \mathrm{~min}$. O sobrenadante foi desprezado e as bactérias foram ressuspendidas em TSB na concentração 0,5 na escala de MacFarland. A seguir, as amostras bacterianas foram colocadas em contado com o soro imune dos animais vacinados e não vacinados por $1 / 2$ hora a $37^{\circ} \mathrm{C}$ na estufa para que ocorresse a opsonização. Após foram acrescentados as células inflamatórias para desencadear o processo de adesão e fagocitose, sendo incubados por $1 / 2$ hora a $37^{\circ} \mathrm{C}$. Posteriormente, foram feitos esfregaços em lâminas, utilizando-se a coloração de Wright, e contadas as células bacterianas associadas às células inflamatórias [7,21]. A contagem foi feita em duplicata, por dois operadores diferentes. Os índices de associação a células foram comparados através do teste $t$ não pareado utilizandose o pacote estatístico GraphPad Instat version 3.05 for Windows [9].

\section{RESULTADOS}

O resultado do número médio de bactérias associadas a células inflamatórias, em cada tratamento e nos diferentes grupos, consta da Tabela 1.

O número médio de Staphylococcus associado a células inflamatórias oriundos da glândula mamária de bovino foi significativamente maior $(\mathrm{p}<0,01)$ nos grupos vacinados, independentemente da cepa bacteriana utilizada. O mesmo foi verificado quando se utilizou a prévia opsonização das cepas bacterianas com soro imune, oriundo de vacas vacinadas. (Tabela 1 e Figura 1).

\section{DISCUSSÃO}

Os animais vacinados apresentaram um aumento significativo no índice de fagocitose e adesão celular, independentemente da cepa de Staphylococcus utilizada, seja coagulase positiva e produtora de pseudocápsulas ou coagulase negativa e não produtora de pseudocápsula. Isto foi verificado pelo acréscimo no número médio de bactérias associadas a células inflamatórias. A maioria destas células são provavelmente neutrófilos, responsáveis pela fagocitose de bactérias na glândula mamária. Desta forma, a vacina utilizada, exerce efeito positivo sobre um dos mecanismos mais aceitos de proteção contra a mastite estafilocócica, ou seja, adesão e a fagocitose por neutrófilos do leite. $\mathrm{O}$ aumento na fagocitose por neutrófilos posteriormente a vacinação contra mastite estafilocócica foi também verificado por outros autores [11].

A média obtida de Staphylococcus aureus associados a células em vacas não vacinadas foi semelhante ao número médio de $S$. aureus por neutrófilo observado por outros autores [7], que foram 4.2 e 5.3 respectivamente.

Paralelamente, observou-se que o número de bactérias associadas a neutrófilos do leite foi maior quando utilizada prévia opsonização das amostras de Staphylococcus com soro imune, tanto no grupo no qual foi utilizada amostra de Staphylococcus coagulase positiva, como coagulase negativa (Tabela $1 \mathrm{e}$ Figura 1). Isto concorda com os achados registrados na literatura [1]. Pode-se explicar isto pela produção de anticorpos antígeno-específicos, especialmente do tipo $\mathrm{IgG} 2$, que proporcionam um aumento na fagocitose por neutrófilos, pois neutrófilos bovino apresentam receptores de membrana para IgG2 [11].

Os resultados obtidos indicam que o uso da vacina pode melhorar a resposta imune em vacas, através de um acréscimo nos índices de adesão e a fagocitose, os quais são considerados importantes na proteção da glândula mamária de bovinos.

\section{CONCLUSÃo}

O uso de vacina comercial contra mastite estafilocócica aumenta a associação de Staphylococcus sp. a células do leite. O prévio tratamento das bactérias com soro imune aumenta significativamente o número de bactérias associadas a células do leite. Portanto, concluiu-se que a utilização de vacina comercial para mastite estafilocócica mostrou-se eficaz para aumentar a associação de células provenientes de vacas vacinadas a Staphylococcus sp., tratado previamente com ou não com soro imune, obtido de vacas vacinadas.

Agradecimento. Ao CNPq pela concessão de Bolsa de Iniciação Científica.

\section{NOTAS INFORMATIVAS}

${ }^{1}$ MASTAPH - IRFA Química e Biotecnologia Industrial Ltda. - Porto Alegre, RS - Brasil. 
Tabela 1. Número médio de bactérias associadas a células de acordo com os tratamentos.

\begin{tabular}{|c|c|c|c|c|}
\hline Grupo & $\begin{array}{l}\text { Staphylococcus } \\
\text { sp. c/ soro }\end{array}$ & $\begin{array}{l}\text { Staphylococcus } \\
\text { sp. s/ soro }\end{array}$ & $\begin{array}{l}\text { S. aureus } \\
\text { c/ soro }\end{array}$ & $\begin{array}{l}\text { S. aureus } \\
\text { s/ soro }\end{array}$ \\
\hline Vacinados & $9,374 a^{1} A^{2}$ & 6,99 a B & 9,238 a $A$ & 6,872 a B \\
\hline Controle & 4,278 b A & 3,846 b B & 4,05 b A & 4,216 b B \\
\hline \multicolumn{5}{|c|}{$\begin{array}{l}{ }^{1} \text { Números na mesma coluna seguidos de letras minúsculas diferentes diferem estatisticamente (Teste de } t \text { não pareado, } \\
\mathrm{P}<0,01 \text { ). } \\
{ }^{2} \text { Números na mesma linha seguidos de letras maiúsculas iguais, diferem estatisticamente (Teste de t não pareado, } \\
\mathrm{P}<0,01 \text { ). }\end{array}$} \\
\hline
\end{tabular}
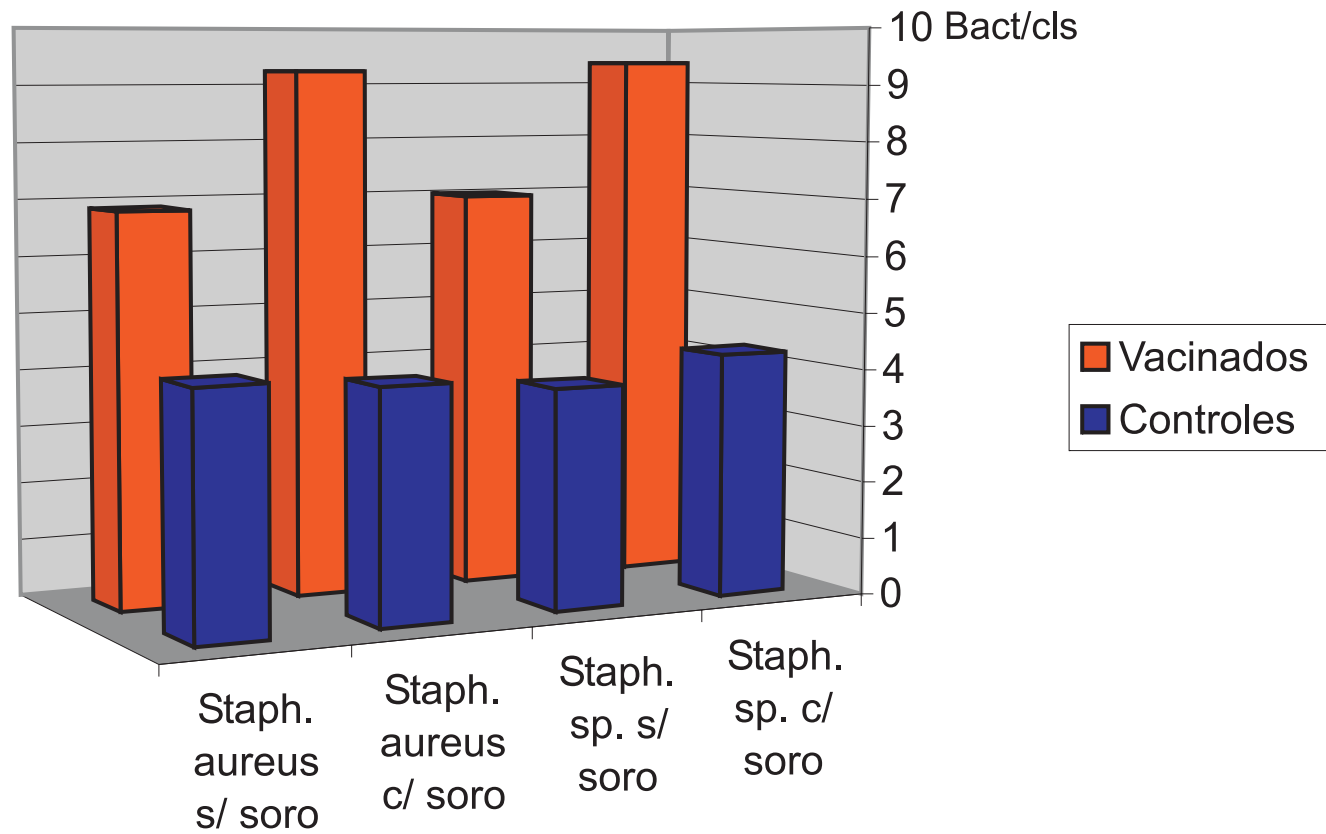

Figura 1. Número de bactérias associadas a neutrófilos mamários.

\section{REFERÊNCIAS}

1 Barrio M.B., Rainard P. \& Poutrel B. 2003. Milk complement and the opsonophagocytosis and killing of Staphylococcus aureus mastitis isolates by bovine neutrophils. Microbial Pathogenesis. 34: 1-9.

2 Bennett R.M., Christiansen K. \& Clifton-Hadley R.S. 1999. Estimating the costs associated with endemic diseases of dairy cattle. Journal of Dairy Research. 66: 455-9.

3 Calzolari A., Giraudo J.A., Rampone H., Odierno L., Frigerio C., Bettera S., Raspanti C., Hernández J., Wehbe M., Mattea M., Ferrari M., Larriestra A. \& Nagel R. 1997. Field trials of a vaccine against bovine mastitis. 2. Evaluation in two commercial herds. Journal of Dairy Science 80: 854-858.

4 Concha C. 2004. Perspectivas da estimulação da resposta imune da glândula mamária bovina In: Dürr J.W., Carvalho M.P. \& Santos M.V. (Eds). O compromisso com a qualidade do leite no Brasil. Passo Fundo: UPF, pp.105-129.

5 Craven N. \& Williams M.R. 1985. Defences of the bovine mammary gland against infection and prospects for their enhancement. Veterinary Immunology and Immunopathology. 10: 71-127.

6 Foster T.J. 1991. Potential for vaccination against infections caused by Staphylococcus aureus. Vaccine. 9: 221-227.

7 Fox L.K., McDonald J.S. \& Corbeil L.B. 1987. Milk neutrophil phagocytosis of Staphylococcus aureus as determined by fluorescent microscopy. Journal of Veterinary Medicine. 34: 549-551.

8 Garcia V., Gomez M., Iglesias M., Sanjuan N., Gherardi M., Cerquetti M.C. \& Sordelli D. 1996. Intramammary immunization with live-attenuated Staphylococcus aureus: microbiological and immunological studies in a mouse mastitis model. FEMS Immunology and Medical Microbiology. 4: 45-51. 
9 GraphPad-Software [computer program]. 1998. Version 3.05 San Diego (CA): GraphPad Software, Inc.

10 Lascelles A.K., Beh K.J. \& Husband A.J. 1980. Origin of Antibody in Mammary secretion with Particular Reference to the IgA system. Advances in experimental medicine and biology. 137: 492-511.

11 Lee J.W., O’Brien C.N., Guidry A.J., Paape M.J., Shafer-Weaver K.A. \& Zhao X. 2005. Effect of a trivalent vaccine against Staphylococcus aureus mastitis lymphocyte subpopulations, antibody production, and neutrophil phagocytosis. The Canadian Journal of Veterinary Research. 69: 11-18.

12 McGhee J.R. \& Mestecky J. 1990. In defence of mucosal surfaces: development of novel vaccines for IgA responses protective at the portals of entry of microbial pathogens. Infectious Diseases Clinics of North America. 2: 315-341.

13 Nordhaug M.L., Nesse L.L., Norcross N.L. \& Gudding R. 1994. A field trial with an experimental vaccine against staphylococcusaureus mastitis in cattle .2. antibody-response. Journal of Dairy Science. 77: 1276-1284.

14 O'Brien C.N., Guidry A.J., Fattom A., Shepherd S., Douglass L.W. \& Westhoff D.C. 2000. Production of antibodies to Staphylococcus aureus serotypes 5, 8, and 336 using poly(DL-lactide-co-glycolide) microspheres. Journal of Dairy Science. 83: 1758-66.

15 Outteridge P.M. \& Lee C.S. 1988. The defence mechanisms of the mammary gland of domestic ruminants. Progress in Veterinary Microbiology and Immunology 4: 165-196.

16 Portes V.M., Dick W., Luciano A.M., Wolff C., Veiga R.F., Costa E., VazA.K. \& Costa U.M. 2006. Diagnósticos microbiológicos de leite mastítico bovino no biênio 2004 - 2005 no Laboratório de Imunologia e Doenças Infecto-contagiosas DOIC do CAV/ UDESC, Lages - SC. In: XII - Ciclo de Atualização em Medicina Veterinária - CAMEV (Lages, Brasil). p.118.

17 Quiroga G.H. 1993. Mecanismos de defensa de la glandula mamaria bovina. Revision de literatura. Revista de Medicina Veterinaria. 74: 288-292.

18 Santos M.V. \& Fonseca L.F.L. 2005. Importância do tratamento no contole da mastite bovina. In: Coleção Gado de Leite. Campinas Quiron, pp.20.

19 Sears P.M. \& Belschner A.P. 1998. Eliminating Staphylococcus aureus intramammary infections using immune enhancement and antibiotic therapy. In: 31st. Annual Conference of the AABP (Washington, EUA). pp.275-276.

20 Vaz A., Paterno M. \& Marca A. 2004. Vaccination of lactating cows improves the efficacy of anti-Staphylococcus intramammary therapy. Le Médecin Vétérinaire du Québec. 34: 169.

21 Vaz A.K. 1994. Some aspects of the immunity to Pasteurella mastitis in sheep. 142 f. London. Dissertação (Doctor in Veterinary Immunology) - Department of Animal Health the Royal Veterinary Collge, University of London.

22 Vaz A.K., Luz E.P. \& Meyer A. 1996. Expressao de capsulas por Staphylococcus sp. causadores de mastite bovina. In: $X V$ Congresso Panamericano de Ciencias Veterinarias - PANVET (Campo Grande, Brasil). p.91.

23 Vaz A.K., Paterno M.R. \& Marca A. 2001. Avaliação da vacina estafilocócica como auxílio à antibioticoterapia de mastite subclínica durante a lactação. A Hora Veterinária. 21: 68-70.

24 Widel P.W. 1994. What about Staphylococcus aureus vaccine - review. Agri-Practice - Bibliothèque de Médecine Vétérinaire. 15: $26-28$. 